\title{
Rheological and tribological approaches as a tool for the development of sustainable lubricating greases based on nano-montmorillonite and castor oil
}

\author{
José Enrique MARTín-ALFOnSO ${ }^{1, *}$, María José MARTín-ALFOnSO ${ }^{1}$, Concepción VALENCIA ${ }^{1}$, María \\ Teresa CUBERES ${ }^{2}$ \\ ${ }^{I}$ Department of Chemical Engineering and Materials Science, Campus de "El Carmen", University of Huelva, Chemical \\ Product and Process Technology Research Center (Pro2TecS), Huelva 21071, Spain \\ ${ }^{2}$ Department of Applied Mechanics and Project Engineering, University of Castilla-La Mancha, Almadén 13400, Spain \\ Received: 11 April 2020 / Revised: 14 May 2020 / Accepted: 21 May 2020 \\ (C) The author(s) 2020 .
}

\begin{abstract}
This study investigates the development of novel montmorillonite/castor oil blends to formulate sustainable lubricating greases to promote the replacement of petrochemicals industry-derived materials by substances obtained from renewable sources. Specifically, the effect of the thickener concentration on the rheological, chemical, thermal, tribological properties, and atomic force microscopy (AFM) microstructure of these systems were studied. The results showed that the C20A nanoclay content could be used to modulate the viscosity values, the linear viscoelastic functions, and tribological properties of these montmorillonite dispersions. In general, these gel-like dispersions exhibited remarkable lubricant properties; the samples showed values of the friction coefficient and wear scars similar or lower than those obtained with model bentonite grease.
\end{abstract}

Keywords: lubricating greases; nanoclay; vegetable oil; rheology; tribology

\section{Introduction}

During the last few years, the depletion of fossil fuels and the general raising of global concern over environmental risks and climate change have aroused a global widespread alarm. For this point, currently, the development of biodegradable materials and products with appropriate properties is a challenging research subject for the material scientists and technologists worldwide. In this sense, there is a huge need of producing "green" products suitable to be used as lubricants with the aim of decreasing the impact that fossil fuels-based materials yield in the nature [1, 2]. Lubricating greases are soft matter multiphase systems that consist of fluid lubricant, traditionally a mineral or synthetic oil, as continuous phase that is physically or chemically entrapped in a network formed by a solid (thickener agent), generally a metal soap. The adequate rheological and tribological behaviour of lubricating greases depends on their formulation and the morphology achieved during their manufacture. With regard to majority components of lubricating greases, it is worthy to note that they are non-renewable materials, there is currently an enormous demand for promoting change in these constituents by substances obtained from renewable sources. One possible approach for improving this point is developing lubricating greases with other constituents, such as clays and vegetable oils.

Vegetable oils are possible substitutes for oils derived from petroleum industry, due to a combination of biodegradability, renewability, and excellent

* Corresponding author: José Enrique MARTÍN-ALFONSO, E-mail: jose.martin@diq.uhu.es 
lubrication properties such as high viscosity index, high lubricity, and low volatility, etc. [3]. In the same way, nanoclays are considered environmentally friendly materials [4] and could be potentially used as effective thickener agents. Among the different types of clays, montmorillonite is one of the most interesting materials for many engineering applications, mainly due to the fact that it is costeffective and easily accessible [5]. Montmorillonite is formed by inorganic layered silicates (octahedral aluminum oxide layer and tetrahedral silicon oxide layer). Many of these layered platelets are stacked into particles. These layered silicates are responsible for the macro-properties of the material. Non-modified montmorillonite is hydrophilic, however, the substitution of ions present in between layers by organic cations could improve the compatibility of clay with a broad range of hydrophobic materials. Due to its small size, it interacts with material at the atomic or molecular level [6]. Over the past years, developing materials or products with montmorillonite for several applications such as biomedical, car industry, as drilling fluids, and as gas-barrier materials has attracted great interest [7], due to the fact that the production of polymer-montmorillonite systems allows adjustments in the mechanical and thermal properties of polymers [8]. Nevertheless, another potential use of this clay could be as thickener agent to develop gel-like dispersions in vegetable oils with suitable mechanical properties [9]. By mixing montmorillonite into the vegetable oil, the compounds of oil may be intercalated into the layer structure of montmorillonite, which form an intercalated structure or an exfoliated structure. Lately, the academia has shown great interest in the development of gel-like dispersions to formulate sustainable lubricating greases, several investigations into the formulation of oleogels thickened with cellulose pulp and other nontoxic polymers have been reported. Martín-Alfonso and Valencia [10] studied the rheological, tribological, and microstructural properties of oleogels based on ethylene-vinyl acetate copolymer (EVA) and two vegetable oils, high-oleic sunflower oil (HOSO) and sunflower oil (SO), and found that the oleogels formulated with SO significantly decreased the wear scars (44\%) compared to oleogels with HOSO. In addition, Martín-Alfonso and Franco [11] investigated the effect of vinyl acetate (VAc) content of EVA copolymer on the rheological and thermal properties of these oleogels, concluding that VAc content and melt flow index of the EVA copolymer significantly affect the oleogels rheological and thermal responses. Nuñez et al. [12, 13] proposed the use of cellulose pulp as thickener agent of vegetable oil media. They found some gels-like dispersions with viscoelastic and tribological characteristics similar with standard lithium greases. However, some weaknesses were observed regarding their mechanical stability, thermal dependence, and leakage tendencies in wheel bearings, even modifying the polarity of cellulose pulp with methyl [14] and ethyl chemical groups [15] to enhance compatibility with the vegetable oil. Gallego et al. [16-18] found that kraft cellulose functionalized with diisocyanate compounds with or without a crosslinked entanglement network was able to retain the base oil significantly improving the rheological properties and mechanical stability. However, the literature missed a comprehensive investigation on the development of oleogel-like dispersions based on organically modified montmorillonite and castor oil blends to formulate sustainable lubricating greases. In this background, the objetive of this work is to study the possibility of using organo modified montmorillonite as gelling agent to develop appropriate systems with castor oil, suitable as lubricating greases. With this in mind, rheological, chemical, thermal, tribological properties, and morphol ogical characterization were carried out on samples. The organoclay content effect on the multifunctional performance was summarized and the optimal formulation of the oleogel-like dispersions based on castor oil and organoclay was determined.

\section{Experimental}

\subsection{Materials}

Vegetable castor oil (viscosity of $211 \mathrm{~mm}^{2} / \mathrm{s}$ at $40{ }^{\circ} \mathrm{C}$ ) supplied by Guinama (Spain) was used as fluid lubricant to formulate dispersions. Commercial organo-montmorillonite Cloisite 20A (designated 
as C20A) produced by Southern Clay Products (Texas) was used as thickener agent in continuous phase. Cloisite 20A was modified with dimethyl dihydrogenated tallow quaternary ammonium chloride to improve its compatibility with nonpolar materials and modifier concentration $92 \mathrm{meq} /$ (100 g of clay). Lubricating grease based on bentonite as thickener agent manufactured by Verkol S.A. (Spain) was used as model system. Compositional details of this lubricating grease just like main properties are presented in Table 1.

Table 1 Composition and basic technical data of bentonite lubricating grease studied.

\begin{tabular}{lll}
\hline \multicolumn{3}{c}{ Test method } \\
\hline Appearance & & Brown \\
Thickener & & Bentonite \\
Base oil & & Mineral oil \\
Viscosity at $40{ }^{\circ} \mathrm{C}\left(\mathrm{mm}^{2} / \mathrm{s}\right)$ & ASTM D-7152 & 160 \\
Dropping point $\left({ }^{\circ} \mathrm{C}\right)$ & IP 396 & $>250$ \\
Oil separation & ASTM D-6184 2.16 \\
Service temperature $\left({ }^{\circ} \mathrm{C}\right)$ & & 20 to 140 \\
\hline
\end{tabular}

\subsection{Manufacture of samples}

To prepare the samples, the organoclay was mixed with castor oil in an open vessel, using a rotorstator turbine (Ultra Turrax T-50, Ika, Staufen, Germany) at rotational speed of 9,000 rpm at room temperature for 10 minutes. Organoclay was previously dried at $60{ }^{\circ} \mathrm{C}$ (60 minutes) and soaked with the castor oil for 60 minutes, at room temperature. Samples containing organoclay in proportions from 20 to $40 \mathrm{wt} \%$ were manufactured.

\subsection{Characterization tests}

Various rheology tests were performed to study the rheological behaviour of samples. All tests were carried out in a controlled-stress rheometer Haake-MARS (Germany) with a rough plate-andplate geometry to avoid slip effects (20 or $35 \mathrm{~mm}$ diameter, depending on the sample, and $1 \mathrm{~mm}$ gap). Stress sweep tests were conducted in a range of $0.1-1,000 \mathrm{~Pa}$ at a frequency of $6.28 \mathrm{rad} / \mathrm{s}$. Smallamplitude oscillatory shear (SAOS) was carried out in a range of $10^{-2}-10^{2} \mathrm{rad} / \mathrm{s}$ by selecting a stress within the linear viscoelastic region (LVR). Flow tests were performed using a shear rate control in a range of $0.01-100 \mathrm{~s}^{-1}$. In addition, to evaluate the thixotropic behaviour of samples, the evolution of viscosity with time was conducted using two shear rates: 0.1 and $10 \mathrm{~s}^{-1}$. Structural recovery tests were conducted at a frequency of $6.28 \mathrm{rad} / \mathrm{s}$, modifying the strain over three steps: in the first step, a strain within the linear viscoelastic region was employed; then a strain of $5 \%$ was applied; finally the firststep conditions were carried out again. All rheological tests were conducted at $23 \pm 0.1{ }^{\circ} \mathrm{C}$, and were replicated at least three times.

Fourier transform infrared (FTIR) spectroscopic analysis was performed using a JASCO FT/IR4200 spectrometer. The spectra were conducted from $400-4,000 \mathrm{~cm}^{-1}$ with 46 repeated scans at a resolution of $1 \mathrm{~cm}^{-1}$ in the transmittance mode.

X-ray diffraction analysis was conducted using a D8 Advance X-ray (Bruker-AXS, Germany) diffractometer at room temperature $(\mathrm{CuK} \alpha$ radiation at $40 \mathrm{kV}, 30 \mathrm{~mA})$ in the range of $1.5^{\circ}-10^{\circ} 2 \theta$. Pure organoclay was tested as a powder, whereas the oleogels were prepared by placing a small amount on a supporting glass slide, which was subsequently flattened to approximately $1 \mathrm{~mm}$ thick by applying pressure, followed by annealing at room temperature. Afterwards, the sample containing slide was located at the centre of a metal holder, externally shaped to be allocated in the instrument.

Thermogravimetric analysis was performed using a Q-50 (TA Instruments, USA), the samples were heated from 30 to $600{ }^{\circ} \mathrm{C}$ at a heating rate of $10{ }^{\circ} \mathrm{C} / \mathrm{min}$ in nitrogen atmosphere. The weight of the samples was $8 \mathrm{mg}$ approximately.

The nanoscale characterization of oleogel-like dispersions was performed by means of atomic force microscopy (AFM), with a commercial AFM instrument (Nanotec). Sample preparation was carried out by spreading a nut of sample across a polished stainless steel sample holder using a glass slide. Topographic and lateral force images were recorded in ambient conditions, operating in contact mode. Olympus rectangular Silicon Nitride cantilevers (spring constant of $0.6 \mathrm{~N} \cdot \mathrm{m}^{-1}$, with a pyramid-like shaped tip) were used.

Penetrations indexes of samples were measured using a Seta Universal penetrometer, model 17000- 
2 (Stanhope-Seta, UK) according to the ASTM D 1403 standard. The penetrations values were converted to full-scale cone penetration values according to the ASTM D217 standard.

Tribological tests were carried out using a tribology cell coupled to a Physica MCR-501-Rheostress rheometer (Anton Paar, Austria). All the details of the configuration of this tribological cell can be found elsewhere [10]. Tests were performed under two normal loads of 10 and $30 \mathrm{~N}$ at $100 \mathrm{rpm}$ for a testing duration of $10 \mathrm{~min}$ at $25^{\circ} \mathrm{C}$. These normal loads were chosen to study the influence of this variable on frictional properties, the values were selected according to similar studies conducted [19]. Five replicates (minimum) were conducted for every test on fresh sample. The morphologies of the worn surfaces were examined in an optical microscope (Olympus BX51) connected to a digital camera (dp70)

\section{Results and discussion}

\subsection{Rheological characterization}

\subsubsection{Linear viscoelastic properties}

To ensure that the oscillatory shear test does not break the sample structure, tests must be conducted at a strain and a stress within the LVR. For this reason, previous stress sweep tests were conducted to ensure that the conditions for linear viscoelastic behaviour were achieved.

Figure 1 shows oscillatory stress sweep tests (normalized storage modulus versus shear stress) of samples as a function of C20A concentration. All samples exhibited typical viscoelastic behaviour, similar to other soft matter multiphase systems like hydrogels, dispersions, emulsions, polymers, and so on where the normalised storage modulus remains constant in the LVR and deformation in the structure is reversible up to a critical stress $\left(\tau_{c}\right)$, in which normalised viscoelastic modulus begins to decrease with increasing shear stress. The LVR in oscillatory shear was considerably influenced by C20A concentration. As might be expected, a relevant increase in $\tau_{\mathrm{c}}$ was achieved when the C20A content was increased, yielding a higher structural colloidal network to shear stress. These results are

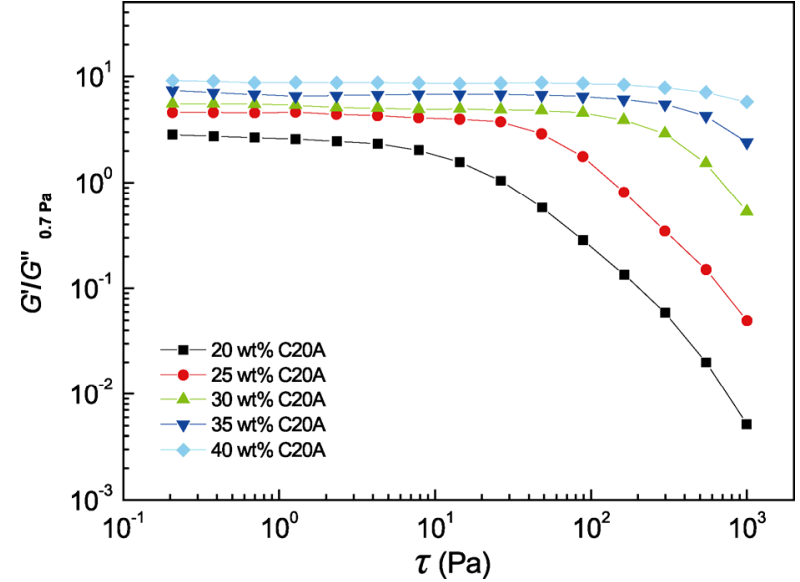

Fig. 1 Dependence of the normalized storage modulus $\left(G^{\prime}=\right.$ $\left.G^{\prime} / G^{\prime \prime}{ }_{0.7 \mathrm{~Pa}}\right)$ with stress $(\tau)$ for gel-like dispersions as function of C20A clay content.

in good agreement with those obtained from other oleogels based on EVA copolymer and vegetable oils [11].

Figure 2 shows the frequency dependence of the linear viscoelastic functions of the SAOS tests with C20A concentration for all samples just like reference lubricating grease. As shown in the figure, the values of storage modulus $\left(G^{\prime}\right)$ were higher than that of loss modulus $\left(G^{\prime \prime}\right)$ for all the oleogel-like dispersions studied and model grease, indicating that the traditional description given for soft solidlike gels behavior of the samples was evident [20]. As expected, the viscoelastic moduli of oleogels increased with $\mathrm{C} 20 \mathrm{~A}$ concentration along the whole frequency range. In general, a similar increasing ratio of both $\mathrm{G}^{\prime}$ and $\mathrm{G}^{\prime \prime}$ was displayed in the (25-40) $w t \%$ C20A range. Yet, the lowest increments of the viscoelastic moduli were found at the lowest C20A concentration studied (20 $\mathrm{wt} \%)$. Moreover, the evolution of viscoelastic moduli was analogous for all the oleogels studied, excepting the loss modulus in the model grease and the sample with the lowest C20A content, where a change in the shape of the mechanical spectrum was clearly displayed. Thus, the oleogels with high C20A concentrations and model grease viscoelastic behaviour correspond to the so called plateau region (higher values of the storage modulus and a minimum in the loss modulus at intermediate frequencies). This region is characteristic of the existence of physical entanglements [21], in this case, it could be attributed to the colloidal network formed by C20A and bentonite, 
where the base oil molecules were adsorbed into the interlayer space of nanoclays, resulting in swelling. The differences between the oleogels and model grease may be ascribed to the different conformation of three-dimensional networks due to the difference among components (types of clays and base oils), as well as the physical interaction between them. This above mentioned evolution of SAOS functions with frequency was obtained for other gel-like dispersions previously studied [12, 13]. Nevertheless, a different behaviour was found for the sample with the lowest C20A content, since a crossover between both moduli a high frequency became visible. This point corresponds to the final of the plateau zone and the starting of the transition zone of the dynamic mechanical spectrum. On the other hand, the evolution with frequency of the loss tangent ( $\left.\tan \delta=G^{\prime \prime} / G^{\prime}\right)$ can be seen in Fig. 2(b). Oleogel-like dispersions with the higher C20A concentration show lower values for the loss $\delta$, especially at high frequencies, indicating an increase in elasticity and the minimum in loss $\delta$ moves to higher frequencies and, therefore, it led to a shift in the viscoelastic response toward lower times. This issue shows that, despite the higher elasticity, in the time scale considered by the higher storage moduli for samples with the higher $\mathrm{C} 20 \mathrm{~A}$ concentrations, the structural links implicated in the transient colloidal network achieved by the samples with lower content of nanoclay are more permanent over the considered time scale, enabling a lower structural rearrangements degree and less dissipative processes.

In short, these results mean that the oleogel-like dispersions with high C20A concentrations ( $>25 \mathrm{wt} \%$ ) and bentonite grease yield a wide plateau region of the mechanical spectrum as corresponds to a higher density of colloidal network formed by the (C20A and bentonite) and base oil molecules, while the sample with the lowest C20A content (20 wt\%) achieves a less compact three-dimensional network, due to lower density of physical network, producing lower viscoelastic moduli and higher values of the loss tangent in SAOS measurements. Figure 3 recaps the influence of C20A concentration on the linear viscoelastic behaviour of oleogels and compares the values with reference lubricating grease through the evolution of plateau modulus

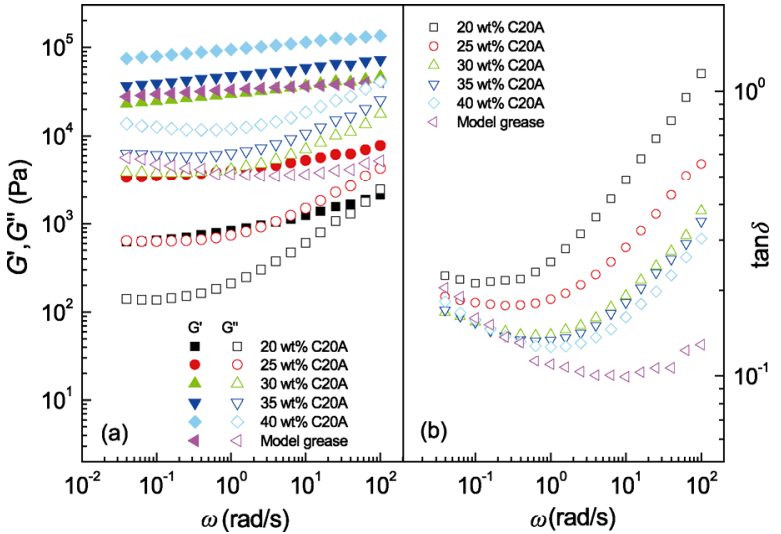

Fig. 2 Frequency dependence of the storage and loss moduli (a) and $\tan \delta(\mathrm{b})$, in the linear viscoelasticity region, for gel-like dispersions containing different $\mathrm{C} 20 \mathrm{~A}$ clay concentrations and commercial grease (filled symbols, $G$ '; empty symbols, $G$ ").

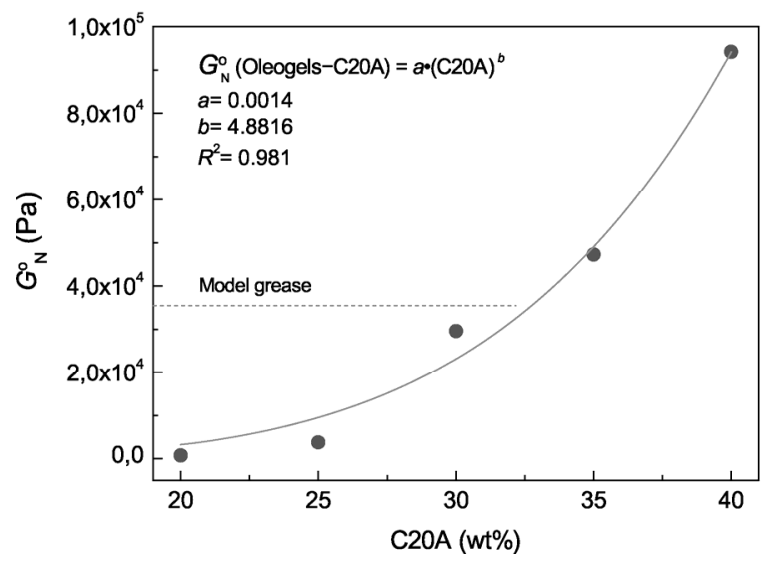

Fig. 3 Evolution of plateau modulus of gel-like dispersions studied, as a function of C20A clay content.

$\left(G_{N}^{\circ}\right)$. The $G_{N}^{\circ}$ could be defined as a measure of the density of the entanglement in the colloidal network, may be approximately calculated from $\tan \delta$ as follows [10]:

$$
G_{\mathrm{N}}^{\mathrm{o}}=\left[G^{\prime}\right]_{\tan \delta \rightarrow \text { minimum }}
$$

As may be seen, plateau modulus clearly increases with $\mathrm{C} 20 \mathrm{~A}$ concentration because of the stronger structural colloidal network and its behaviour can be suited fairly well with a power-law model:

$$
G_{\mathrm{N}}^{\mathrm{o}}=a \cdot(\mathrm{C} 20 \mathrm{~A})^{b}
$$

The adjustable parameters ( $a$ and $b$ ) are shown in Fig. 3. Interestingly, to achieve similar $G_{N}^{o}$ values to the ones attained with the model grease, it is necessary a $30 \mathrm{wt} \%$ of C20A content.

\subsubsection{Flow curves and thixotropic behaviour}

Figure 4(a) displays the flow curves of oleogel-like 

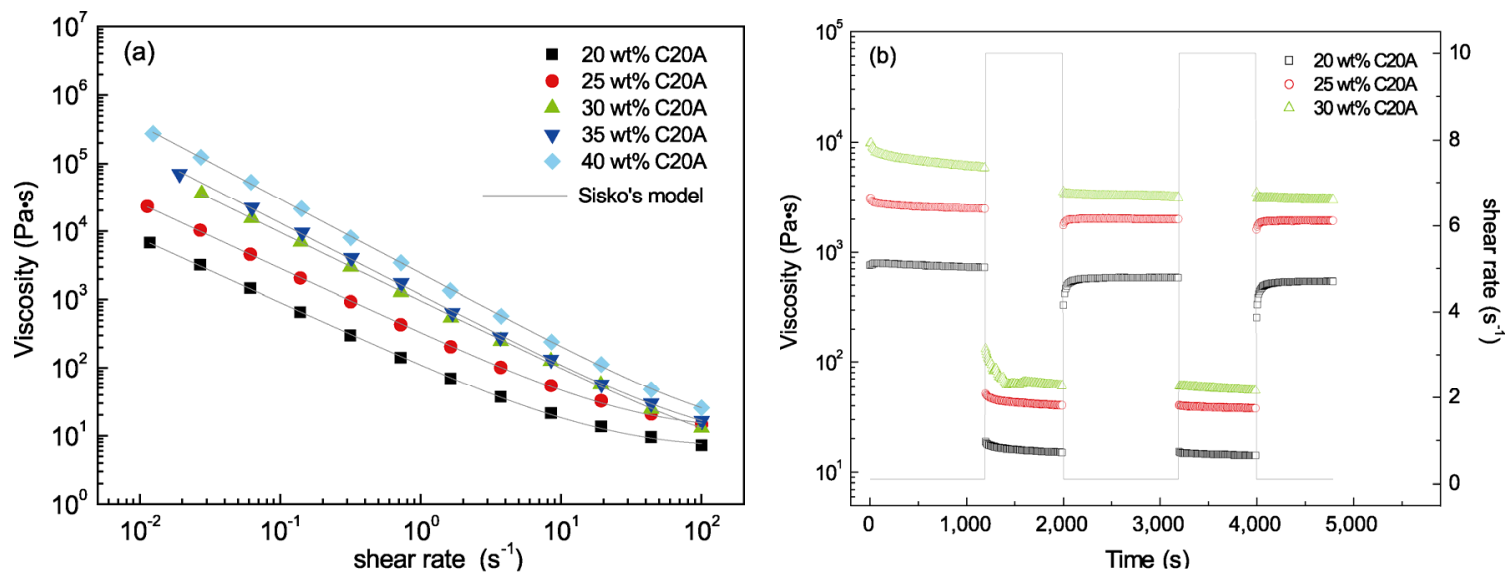

Fig. 4 (a) Viscous flow curves of gel-like dispersions as function of C20A clay content and (b) thixotropic and shear thinning properties of gel-like dispersions measured by plotting viscosity over time and at changing shear rates of $0.1 \mathrm{~s}{ }^{1}$ and $10 \mathrm{~s}{ }^{1}$.

dispersions containing different C20A concentrations. As may be seen, all oleogels showed a shear-thinning response with a tendency to reach a limiting viscosity in the high shear rate region. This flow behavior fitted fairly well to the Sisko model with $R^{2}$ values above 0.99:

$$
\eta=m \dot{\gamma}^{n-1}+\eta_{\infty}
$$

where $m$ is a parameter related to the consistency of the sample, $n$ is a parameter related to the slope of the power-law region, being the so called flow index and $\eta_{\infty}$ stands for infinite shear viscosity. All fitting parameters obtained from the fit to model for all oleogels are shown in Table 2. Samples exhibited increasing values of consistency index, $m$, with an increase in the C20A content, which is a result of increasing viscosity. However, the flow index did not show relevant modifications with changes in C20A concentration of the samples.

Moreover, the shear thinning behaviours of oleogellike dispersions were found out by investigating the samples viscosity evolution with time at low

Table 2 Rheological parameters for gel-like dispersions studied.

\begin{tabular}{|c|c|c|c|c|c|}
\hline Samples & $\begin{array}{c}m \\
\left(\mathrm{~Pa} \cdot \mathrm{s}^{n}\right)\end{array}$ & $n$ & $\begin{array}{c}\eta_{\infty} \\
(\mathrm{Pa} \cdot \mathrm{s})\end{array}$ & $\begin{array}{c}\text { Destruction } \\
(\%)\end{array}$ & $\begin{array}{c}\text { Recovery } \\
(\%)\end{array}$ \\
\hline $20 \mathrm{wt} \% \mathrm{C} 20 \mathrm{~A}$ & 103.6 & 0.063 & 6.307 & 58.11 & 60.79 \\
\hline $25 \mathrm{wt} \% \mathrm{C} 20 \mathrm{~A}$ & 316.4 & 0.046 & 11.44 & 61.13 & 60.96 \\
\hline $30 \mathrm{wt} \% \mathrm{C} 20 \mathrm{~A}$ & 954.9 & 0.024 & 3.605 & 73.47 & 50.58 \\
\hline $35 \mathrm{wt} \% \mathrm{C} 20 \mathrm{~A}$ & 1161.5 & 0.007 & 7.711 & 76.10 & 50.12 \\
\hline $40 \mathrm{wt} \% \mathrm{C} 20 \mathrm{~A}$ & 2405.5 & 0.003 & 9.772 & 76.35 & 48.58 \\
\hline Model grease & 810.3 & 0.014 & 3.082 & 75.27 & 49.32 \\
\hline
\end{tabular}

$\left(0.1 \mathrm{~s}^{-1}\right)$ and high shear rates $\left(10 \mathrm{~s}^{-1}\right)$. As may be seen in the Fig. 4(b), a slight continuous decrease in the viscosity was found initially at the lower shear rate. Then, a decrease in the viscosity values appeared due to structural break of sample when the shear rate was increased. Nevertheless, the microstructural network showed some reorganization and the viscosity values increased when the shear rate decreased again. These outcomes prove that these oleogels displayed thixotropic properties with a significant shear thinning index, which are in good agreement with those displayed in flow curves, just like a partial recuperation of microstructural network. This specific property of oleogels could be important for applications where a tunable microstructural break and recovery is required like lubrication of mechanisms with grease in rolling element bearings.

\subsubsection{Structural recovery}

Figure 5 shows the dependence of the complex modulus $\left(G^{*}\right)$ with time for all samples as a function of C20A content. As may be observed, the evolution of $G^{*}$ was analogous for all the samples studied where a first zone with constant $G^{*}$ values with time was always achieved. After that time, the complex modulus decreased and finally the complex modulus increased again due to partial or total recovery of structural network. The degrees of recovery and destruction for samples were estimated with the aid of the following equations: 


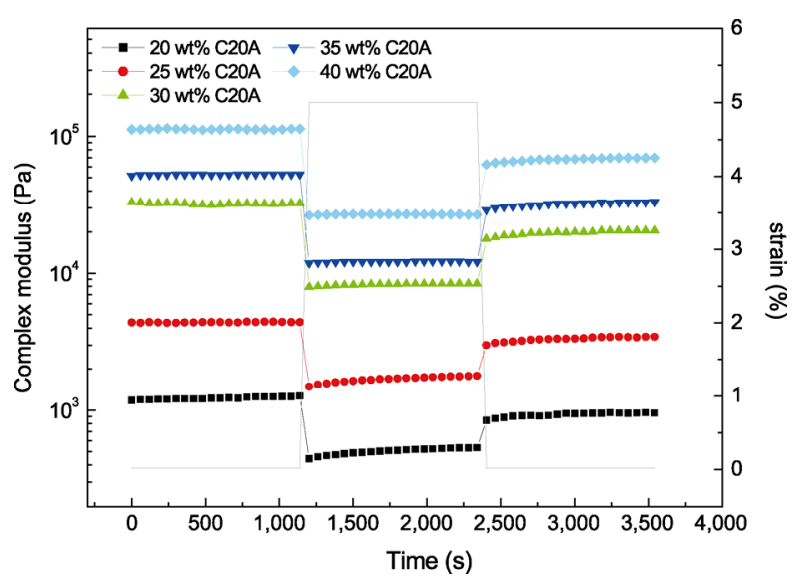

Fig. 5 Complex modulus $\left(G^{*}\right)$ decay, at frequency of $1 \mathrm{~Hz}$, after changing shear strain from the linear to the nonlinear viscoelastic region and further recovery when the former shear strain is reimposed for the evolution of complex modulus for gel-like dispersions containing different C20A clay content.

$$
\begin{gathered}
\operatorname{Destruction}(\%)=\frac{G_{\mathrm{o}}^{*}-G_{1}^{*}}{G_{\mathrm{o}}^{*}} \cdot 100 \\
\operatorname{Recovery}(\%)=\left(\frac{G_{2}^{*}-G_{1}^{*}}{G_{\mathrm{o}}^{*}-G_{1}^{*}}\right) \cdot 100
\end{gathered}
$$

where $G_{o}^{*}$ is the initial complex modulus value within the LVR; $G_{1}^{*}$ is the second complex modulus value without LVR; and $G_{2}^{*}$ is the complex modulus value within the LVR again. Table 2 displays the degree of recovery and destruction of samples estimated from Eqs. (4) and (5). The degree of rheo-destruction increases with the C20A content, while the recovery percentage decreases. These results suggest that, when the colloidal network is broken, the ability of this microstructure to physically entrap fluid lubricant (castor oil) is decreased, and a partial or total separation of the gelling agent and the vegetable oil could be observed. Similar result was found in lubricating greases based on lithium soap and recycled low-density polyethylene (LDPE) with mineral oil [22]. In this sense, it has been highlighted that the shear strain degree leads to a critical effect respecting the microstructural network recovery of the oleogel-like dispersions.

\subsection{Chemical, thermal properties, and microstructure}

FTIR spectra of several oleogels as a function of C20A concentration with the pure materials (C20A organoclay and castor oil) are shown in Fig. 6. Castor oil displays various characteristic FTIR

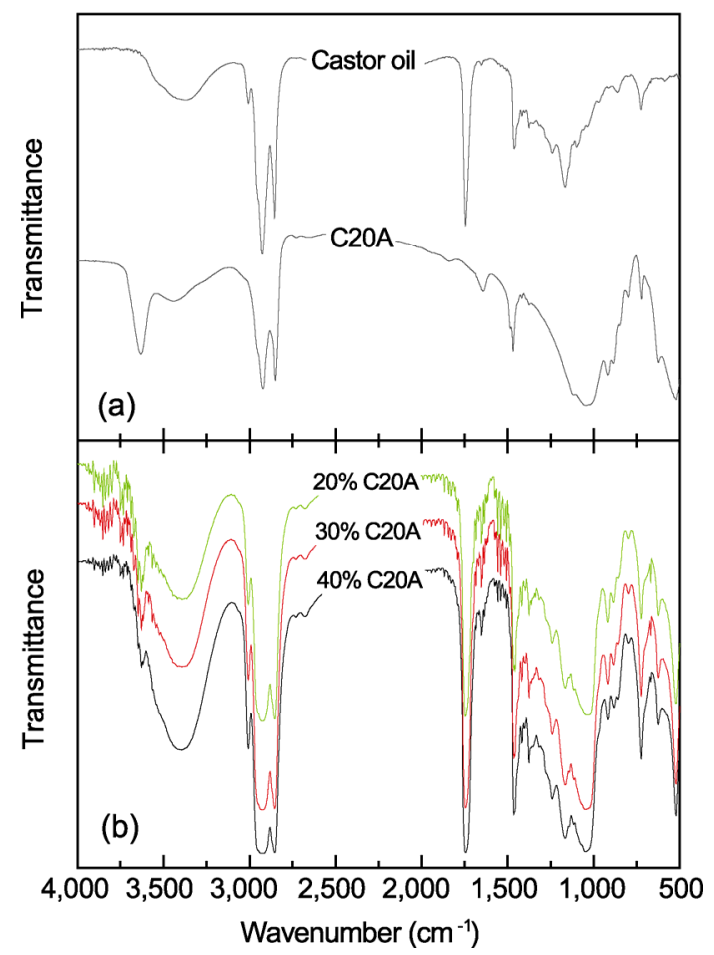

Fig. 6 (a) FTIR spectra of the C20A nanoclay and castor oil; (b) FTIR spectra for selected gel-like dispersions as a function of C20A clay content.

transmittance bands, the $-\mathrm{OH}$ related peak of ricinoleate occurs at $3,381 \mathrm{~cm}^{-1}$, the peak at 3,010 $\mathrm{cm}^{-1}$ is attributed to the presence of $\mathrm{C}=\mathrm{C}$. The dominant absorption peaks at 2,927 and 2,851 $\mathrm{cm}^{-1}$ were respectively attributed to the $\mathrm{CH}_{3}$ and $\mathrm{CH}_{2}$ and the peak at $1,745 \mathrm{~cm}^{-1}$ was ascribed to $\mathrm{C}=\mathrm{O}$ (carbonyl group) stretching vibration absorption $[23,24]$. For the organoclay, apart from the typical $\mathrm{Si}-\mathrm{O}$ stretching vibration band of the non-modified montmorillonite at 1,038 and $914 \mathrm{~cm}^{-1}$, the spectrum shows one absorption band near $3,631 \mathrm{~cm}^{-1}$ related to inner hydroxyl groups, lying between the tetrahedral and octahedral sheets and the characteristic absorption bands of the alkylammonium modified clay: the symmetric and asymmetric $\mathrm{C}-\mathrm{H}$ stretching bands at 2,922 and 2,849 $\mathrm{cm}^{-1}$ and a characteristic $\mathrm{C}-\mathrm{H}$ bending vibration of the $(\mathrm{CH} 3) 4 \mathrm{~N}^{+}$cation at $1,469 \mathrm{~cm}^{-1}[25,26]$. Obviously, the main characteristic peaks of these spectra could also be seen for C20A dispersions (Fig. 6(b)), this fact corroborates the presence of all components in samples.

X-ray diffraction (XRD) was used for determining the interaction degree by interlayer spacing of organoclay in a vegetable oil continuous phase. 
XRD patterns of selected oleogels as a function of C20A concentration and pure C20A organoclay are displayed in Fig. 7. The determination of the spaces between structural clay layers of samples can be estimated by Bragg equation:

$$
\sin \theta=\frac{n \lambda}{2 d}
$$

where $\lambda$ is the wavelength of the $\mathrm{X}$-ray radiation used in the diffraction experiment, $d$ is the spacing between diffractional lattice planes, $n$ is the order of diffraction, and $\theta$ is the measured diffraction. As may be seen, C20A presents one characteristic $\mathrm{d}_{001}$ peak at $2 \theta=3.65^{\circ}$, corresponded to the layer spacing of $2.40 \mathrm{~nm}$, together with a small peak at $2 \theta=7.22^{\circ}$, typical of non-modified montmorillonite [27]. In the XRD patterns of the oleogels, the principal characteristic diffraction peak of the organoclay has shifted to the lower angles $(2 \theta=$ $2.45^{\circ}$ ) corresponding to d-spacing of $3.57 \mathrm{~nm}$. This change in layer spacing indicates that the internal quaternary alkyl ammonium groups in the clay and vegetable oil have an excellent affinity, which promotes their introduction between the layers. The concentration of organoclay has minor influence on the maximum peak position. Nevertheless, the maximum peak intensities grow up with the increase of C20A content. This peaks intensity is a consequence of the diffraction of the parallel assembly of the nanoclay layers which was affected by the extent of exfoliation or intercalation of oil molecules.

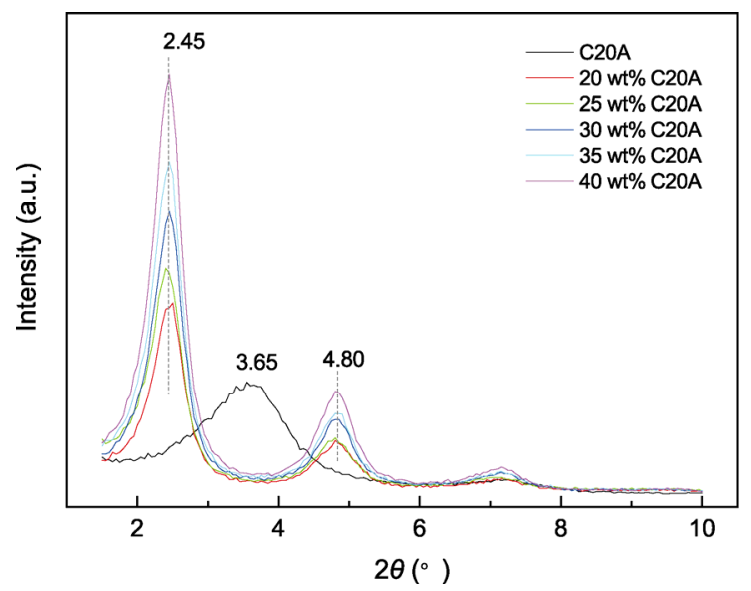

Fig. 7 XRD for gel-like dispersions as a function of C20A clay content. Pure C20A intensity profiles are also included for reference.
Thermogravimetric analysis was carried out to investigate the effect of organoclay content on the samples thermal stability. Figure 8 shows the mass loss (TGA) and mass loss rate (DTG) curves of pure C20A organoclay, castor oil, and selected oleogels as a function of organoclay content. Thermal decomposition of the vegetable oil, started in the range of $300{ }^{\circ} \mathrm{C}$ and ended at about $495{ }^{\circ} \mathrm{C}$, corresponding to the decomposition processes and/ or volatilization of the ricinoleic fatty acid present in the composition of castor oil and successive degradation compounds. Concerning the organoclay C20A, its thermal decomposition presents two stages of mass loss. Firstly, an initial mass loss at approximately $50{ }^{\circ} \mathrm{C}$, which could be ascribed to water loss, and a second main stage and a shoulder, between 180 and $460{ }^{\circ} \mathrm{C}$, which is ascribed to organo-modifier degradation (quaternary ammonium salt) [28]. Similarity to thermal decomposition of C20A, the decomposition of oleogels has two different stages. The first stage (between 275$407^{\circ} \mathrm{C}$ ) is attributable with the thermal volatilization of the vegetable oil (castor oil). The second stage (between $407-460^{\circ} \mathrm{C}$ ) may be associated with organomodifier degradation. The overall TGA data including the temperatures at which $5 \%\left(T_{5}\right), 10 \%$ $\left(T_{10}\right)$ degradation occur, maximum rate mass loss temperature $\left(T_{\max }\right)$ and the residue $(\mathrm{CY})$ at $600{ }^{\circ} \mathrm{C}$ are summarized in Table 3. There is about $65.8 \mathrm{wt} \%$ the residue at $600{ }^{\circ} \mathrm{C}$ for $\mathrm{C} 20 \mathrm{~A}$, which is in agreement with the theoretical presence of 92 meq of organic ammonium salt. The data also show that the content

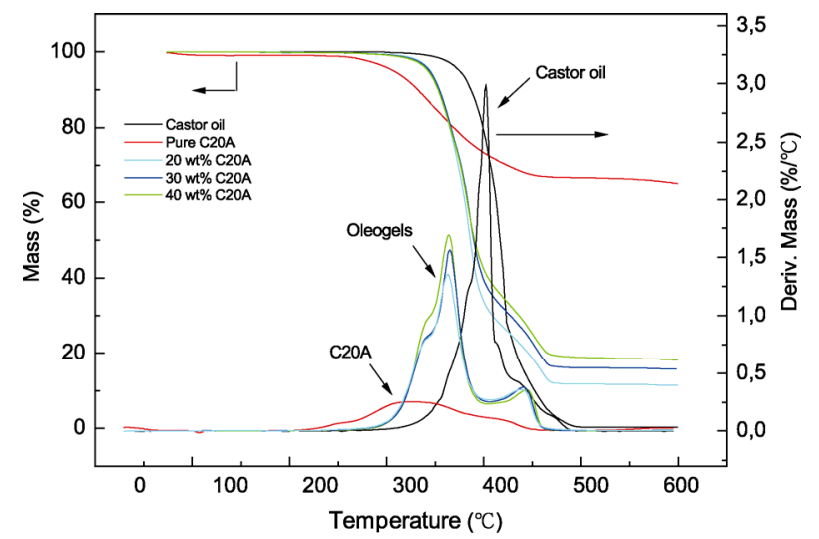

Fig. 8 TGA/DTG thermograms for pure C20A nanoclay, castor oil, and gel-like dispersions as a function of C20A clay content. 
Table 3 Thermal property data of C20A nanoclay, castor oil, and gel-like dispersions.

\begin{tabular}{lcccc}
\hline Samples & $T_{5}\left({ }^{\mathrm{o}} \mathrm{C}\right)^{\mathrm{a}}$ & $T_{10}\left({ }^{\mathrm{o}} \mathrm{C}\right)^{\mathrm{b}}$ & $T_{\max }\left({ }^{\mathrm{o}} \mathrm{C}\right)^{\mathrm{c}}$ & $\mathrm{CY}^{\mathrm{d}}$ \\
\hline Castor oil & 353 & 366 & 402 & 0.28 \\
C20A & 280 & 307 & $331 / 450$ & 65.8 \\
20 wt\% C20A & 321 & 332 & $363 / 441$ & 11.4 \\
25 wt\% C20A & 320 & 331 & $364 / 442$ & 13.5 \\
$30 \mathrm{wt} \%$ C20A & 320 & 331 & $365 / 441$ & 15.8 \\
$35 \mathrm{wt} \%$ C20A & 319 & 330 & $364 / 442$ & 17.6 \\
$40 \mathrm{wt} \%$ C20A & 318 & 329 & $364 / 444$ & 18.3 \\
\hline
\end{tabular}

a Temperature at 5 mass $\%$ loss.

${ }^{\mathrm{b}}$ Temperature at 10 mass \% loss.

${ }^{\mathrm{c}}$ Maximum mass loss temperature.

${ }^{\mathrm{d}} \mathrm{CY}$ : char yield, the residue after TGA analysis at a maximum temperature of $600{ }^{\circ} \mathrm{C}$.

of C20A has a minimum influence on the $T_{5}$ and $T_{10}$ (temperature at 5 and 10 mass $\%$ loss) and $T_{\max }$ (maximum mass loss temperature), only $\pm 2{ }^{\circ} \mathrm{C}$ of the oleogels. However, as can be observed, there is an increase on the residue of the oleogels when the C20A concentration grows up.

Figure 9 shows AFM topographic images recorded scanning from left to right (a) and from right to left (b), and lateral force images, (c) recorded simultaneously with (a), and (d) recorded simultaneously with (b). The topography reveals a flat surface, presumably from a CA20 particle, on top of which linear features, presumably steps or defects can be distinguished, characterized by $30^{\circ}$ and $60^{\circ}$ angles. At the particle edge, at the left-hand side, a protrusion is distinguished in the topography (whiter in the image). As indicated by the traces on (a) and (b), the protrusion is soft and loosely bound, as it is possible to slightly displace it to the left and to the right with the tip while scanning from right to left (a) and from left to right (b) respectively. Interestingly, the lateral force images (c) and (d) do not reveal surface regions with different frictional contrast, nor even at the particle edge. Figure 10 shows a close-up view of the particle edge region; the images in Figs. 10(a)-10(c) were recorded over the region outlined by the square in Fig. 9(c), and the images in Figs. 10(d)-10(f) were recorded over the region outlined by the squere in Fig. 10(b). The surface features are better resolved in the lateral force images. In those, steps characteristics of clay material are clearly distinguished. Interestingly, no regions with a different frictional contrast are distinguished here either. It could be attributed to the clay surface being totally covered by the castor oil.

\subsection{Lubrication properties}

The influence of thickener agent (C20A) concentration on some lubrication efficiency related properties of resulting oleogel-like dispersions has been studied in accordance with some tribological tests. Table 4 displays the consistency and National Lubricating Grease Institute (NLGI) grade values of all studied dispersions. The NLGI number is a parameter related to the lubricating grease consistency based on the ASTM D217 penetration at $25^{\circ} \mathrm{C}$ (betwe en 000-6), being the so called NLGI grade [29]. The most common NLGI grade is 2, which is recom mended for most applications. However, softer grades (0-1) could be applied to improve the pumpability, for example. It is seen that increasing C20A concentration from $20 \mathrm{wt} \%$ to $40 \mathrm{wt} \%$ causes NLGI grade to increase from 000 to 4, moreover, sample with $30 \mathrm{wt} \%$ C20A and standard model bentonite grease show similar consistency value (NLGI grade 2).
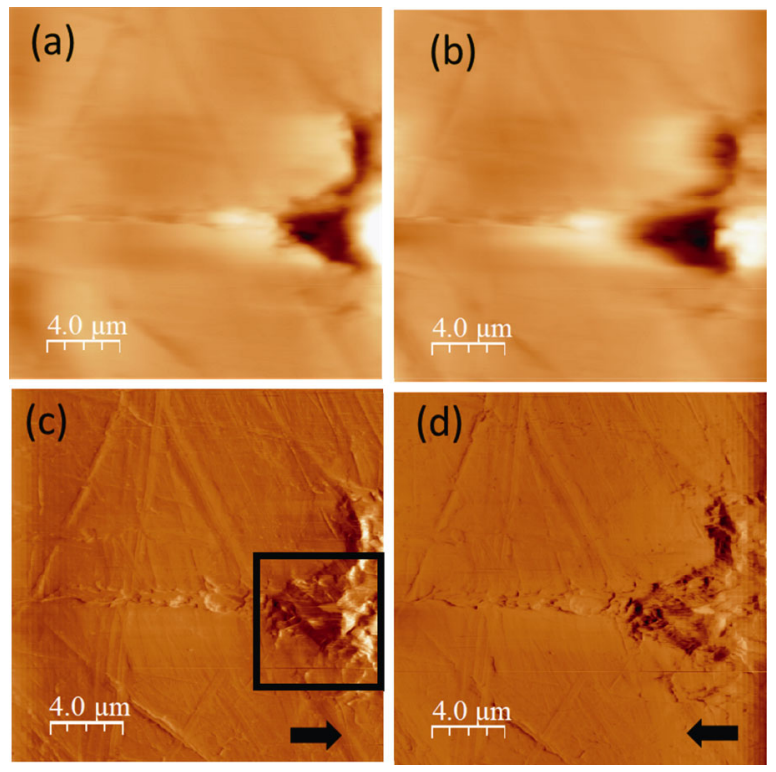

Fig. 9 AFM/LFM micrographs for $30 \mathrm{wt} \% \mathrm{C} 20 \mathrm{~A}$ gel-like dispersion. (a, b) AFM topographic image. The coulour scale ranges 1 micron. (c, d) LFM images recorded simultaneously with $(a, b)$ scanning from left to right, and from right to left, respectively. (The square in (c) indicates the area over which the AFM/FFM images in Figs. 10(a-c) were recorded). 

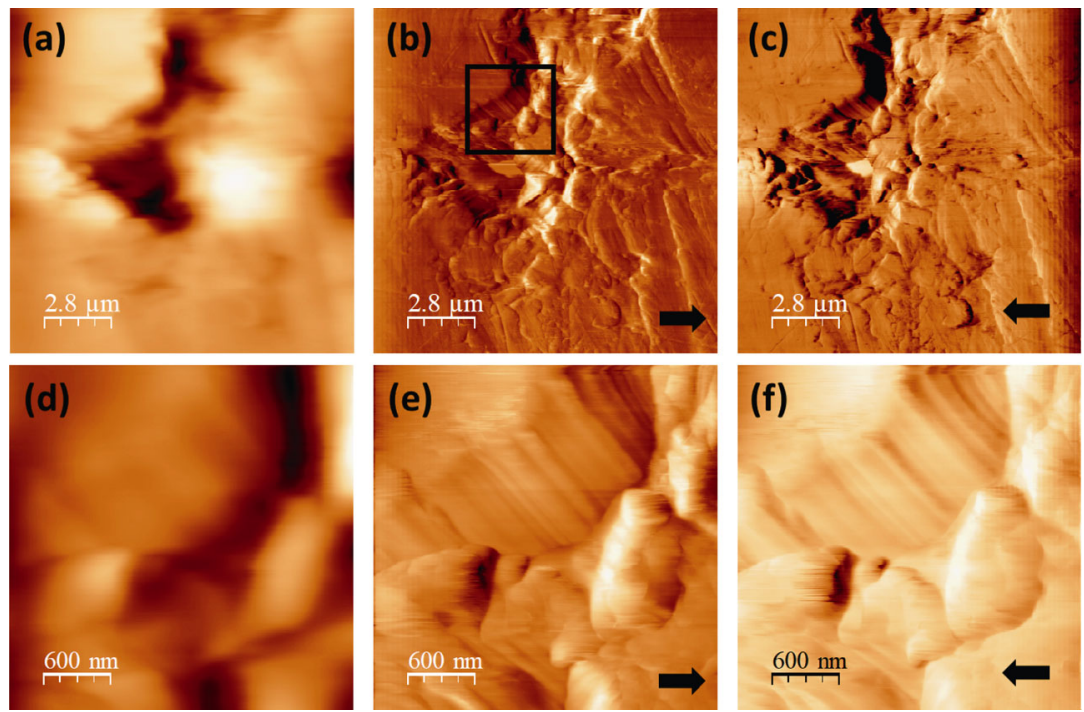

Fig. 10 AFM (a) and LFM (b, c) images recorded over the region outlined by the square in Fig. 9(c). (The square in (b) indicates the area over which (d-f) images were recorded); AFM (d) and LFM (e, f) images recorded over the same surface area of the square in (b).

Table 4 NLGI consistency numbers, penetration and friction coefficient values for gel-like dispersions studied.

\begin{tabular}{ccccc}
\hline Samples & $\begin{array}{c}\text { Penetration } \\
\text { index }(\mathrm{dmm})\end{array}$ & $\begin{array}{c}\text { NLGI } \\
\text { grade }\end{array}$ & \multicolumn{2}{c}{ Friction coefficient } \\
\hline $20 \mathrm{wt} \% \mathrm{C} 20 \mathrm{~A}$ & 498 & 000 & 0.081 & 0.069 \\
$25 \mathrm{wt} \% \mathrm{C} 20 \mathrm{~A}$ & 392 & $00-0$ & 0.124 & 0.071 \\
$30 \mathrm{wt} \% \mathrm{C} 20 \mathrm{~A}$ & 287 & 2 & 0.142 & 0.076 \\
$35 \mathrm{wt} \% \mathrm{C} 20 \mathrm{~A}$ & 247 & 3 & 0.156 & 0.082 \\
$40 \mathrm{wt} \% \mathrm{C} 20 \mathrm{~A}$ & 198 & 4 & 0.179 & 0.085 \\
Model grease & 280 & 2 & 0.156 & 0.123 \\
\hline
\end{tabular}

On the other hand, the applicability of these systems as lubricating greases was studied with a tribological test. Figure 11 displays the friction curves of steel/steel contact under lubrication at 10 and $30 \mathrm{~N}$ for castor oil, oleogel-like dispersions containing different $\mathrm{C} 20 \mathrm{~A}$ concentrations as well as standard model grease. For oleogel with the lowest C20A concentration, firstly, the friction coefficient dips and then progressively diminishes to a constant value (see Fig. 11(a)). Commonly, this behaviour has been ascribed to the formation of the protective lubricating film due to the rubbing action [30]. Nervertheless, other selected oleogels evaluated produce an increase of the friction coefficient after the first drop, as a consequence of the effect of resulting wear debris.

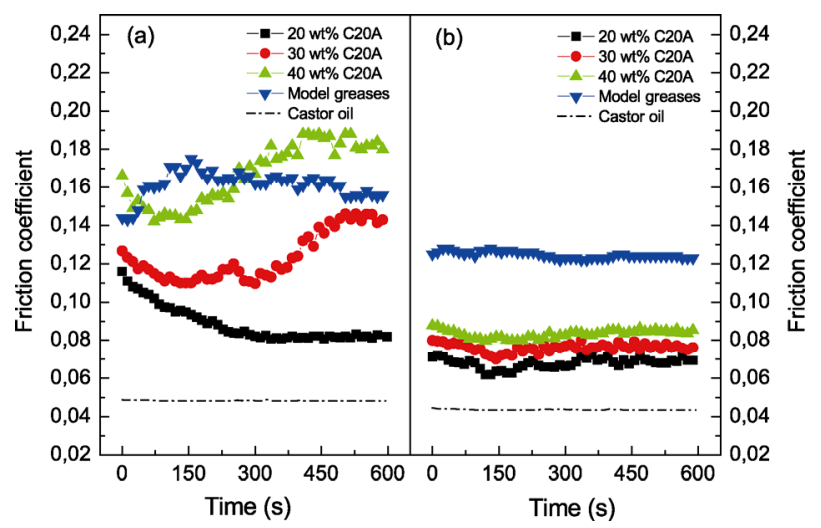

Fig. 11 Evolution of the friction coefficient with time, at $25^{\circ} \mathrm{C}$ and (a) a normal load $(10 \mathrm{~N})$ and (b) a normal load of $30 \mathrm{~N}$, for selected gel-like dispersions as a function of C20A clay content (constant rotational speed:100 rpm).

Table 4 displays the friction coefficient values achieved under loads (10 and $30 \mathrm{~N}$ ) for all the dispersions investigated. An increase in the friction coefficient values of the samples upon increasing the C20A concentration and decreasing normal load was observed. It is worth mentioning that when the normal load is increased up to $30 \mathrm{~N}$, oleogels present friction coefficient values similar among themselves but lower than the ones obtained with the standard model grease. These results confirm that the tribological behavior of samples is influenced by $\mathrm{C} 20 \mathrm{~A}$ concentration in the formulation. 
Oleogels with lower viscosity and viscoelastic moduli have a stronger capacity to form a protective lubricating film because of the rubbing action compared to oleogels with higher viscosity and viscoelastic moduli, presumably because the interactions between C20A and castor oil hamper the motion of vegetable oil molecular chain. In addition, Fig. 12 displays the friction coefficient versus consistency index $(m)$ in order to investigate the relationship among rheological and tribological properties of oleogel-like dispersions. As may observed, the oleogels with lower consistency index achieved lower friction coefficients but the differences among values are rather small, especially for the higher load, a linear tendency between these parameters was found. Similar behaviour was obtained for mineral and synthetic commercial engine oils [31] and other oleogels based on ethylene vinyl acetate polymer as thickener agent and high-oleic sunflower vegetable oil [10]. In order to complete the tribological study, Fig. 13 shows optical images of the worn surfaces lubricated with selected oleogels and model bentonite grease. In all cases, a rounded wear marks arise and many micro-pits and micro-furrow ditches along the sliding direction, which are dominated by abrasive wear. A slightly decrease in the wear degree and the contact area upon increasing the C20A concentration was observed. However, the normal load yielded a considerable effect, the stronger normal force applied, the narrower the wear scar is, as can be observed in the figure, which are in agreement with friction coefficient

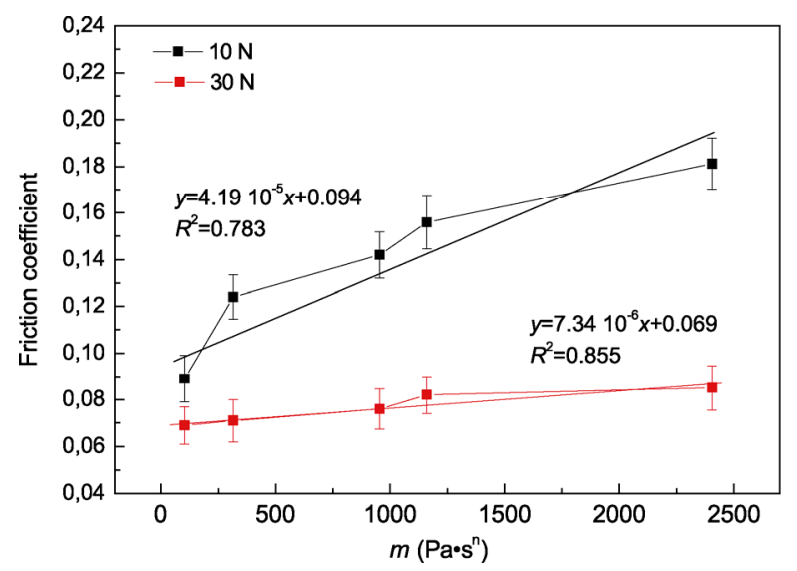

Fig. 12 The consistency index $(m)$ versus friction coefficient plot for oleogels as a function of the normal load applied.
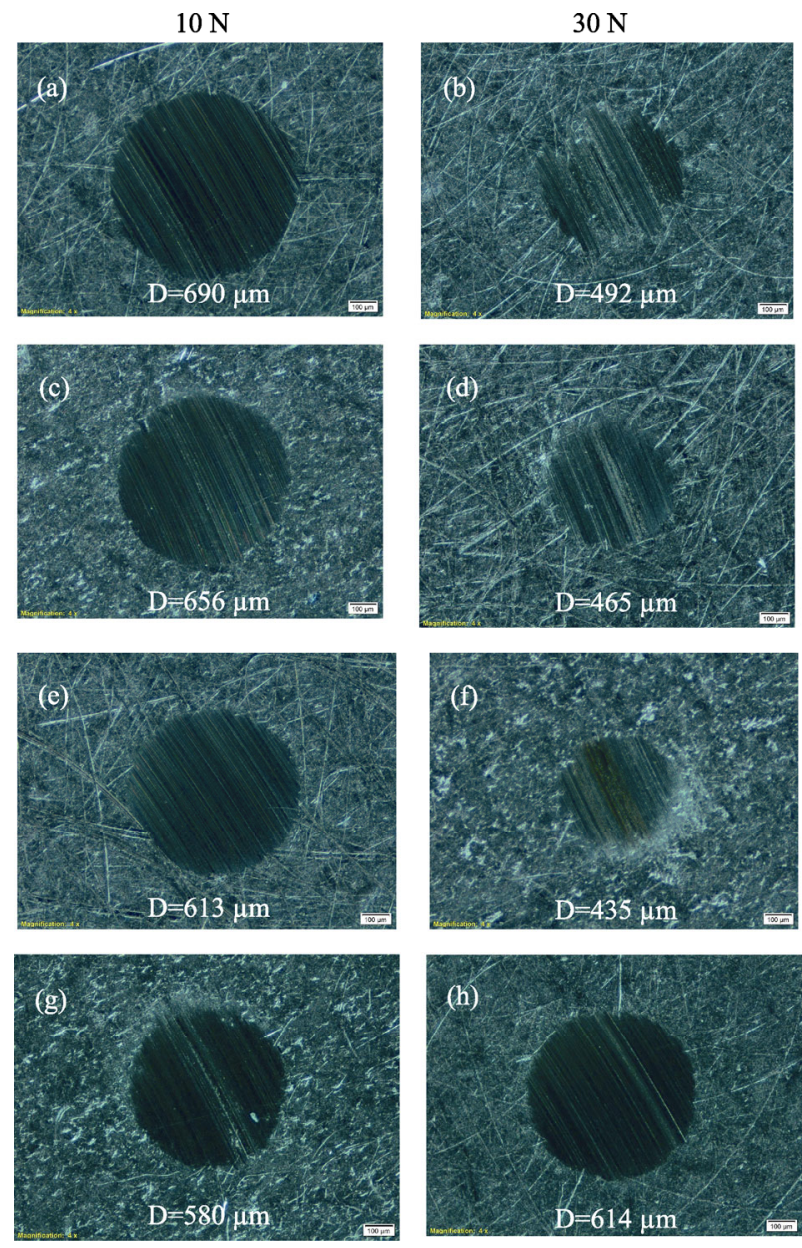

Fig. 13 Optical images and corresponding average diameter of the worn plate surface for steel/steel contacts obtained at $23{ }^{\circ} \mathrm{C}$, constant rotational speed $(100 \mathrm{rpm})$ and different normal loads (10 and $30 \mathrm{~N})$ using selected gel-like dispersions: (a, b) $20 \mathrm{wt} \% \mathrm{C} 20 \mathrm{~A}$; (c, d) $30 \mathrm{wt} \% \mathrm{C} 20 \mathrm{~A}$; (e, f) $40 \mathrm{wt} \% \mathrm{C} 20 \mathrm{~A} ;(\mathrm{g}, \mathrm{h})$ model grease.

values previously achieved. In addition, oleogels yield values of the wear scar diameter comparable to reference bentonite lubricating grease.

\section{Conclusions}

An approach to the development and characterization of new oleogels based on organically modified montmorillonite and castor oil applicable as sustainable lubricating greases has been successfully tested for the first time. From a rheological point of view, samples displayed significant characteristics such as thixotropy, shear thinning and total or partial microstructure network recovery. Rheological behaviour encountered in model bentonite lubricating grease 
was loaded in all formulations studied, giving rise to three-dimensional network corresponding to the plateau region in the dynamic mechanical spectrum. Linear viscoelastic response was also highly dependent on the concentration of nanoclay, thus, an empirical power-law equation using the "plateau", $G_{\mathrm{N}}^{\circ}$, modulus was found.

These results were corroborated by XRD analysis and AFM observations, where well-developed interspersed clay structures of well-dispersed particles in a vegetable oil phase were showed. All samples showed shear thinning behaviour and a trend to reach infinite viscosity at higher shear rate, which fitted fairly well the Sisko model. Thermal degradation of oleogels showed two stages which encompasses the thermal decomposition and/or volatilization of both the vegetable oil and the nanoclay. Tribological behaviors of oleogels are affected by the thickener agent concentration and both the friction coefficient and the wear scars were, in most cases, comparable to that obtained with model bentonite grease.

To sum up, it may be demonstrated that the use C20A montmorillonite and castor oil for the manufacture of oleogel-like dispersions can be an excellent alternative to promote the replacement of synthetic or fossil fuel-derived products by substances obtained from renewable resources. The C20A nanoclay concentration could be used to modulate the NLGI values, the linear viscoelastic functions, and tribological properties of these dispersions. Oleogel with mass proportion of $30 \%$ displayed the optimal rheological and tribological properties. Nevertheless, it should be highlighted that further research is necessary to obtain more in-depth knowledge around the rheological and tribological properties with the high-temperature, and nanoscale structure and frictional response from AFM/FFM measurements, so as to develop theory-based models concerning the interaction of C20A nanoclay and castor oil to test the true suitability of these formulations as lubricating greases.

Open Access: This article is licensed under a Creative Commons Attribution 4.0 International License, which permits use, sharing, adaptation, distribution and reproduction in any medium or format, as long as you give appropriate credit to the original author(s) and the source, provide a link to the Creative Commons licence, and indicate if changes were made.

The images or other third party material in this article are included in the article's Creative Commons licence, unless indicated otherwise in a credit line to the material. If material is not included in the article's Creative Commons licence and your intended use is not permitted by statutory regulation or exceeds the permitted use, you will need to obtain permission directly from the copyright holder.

To view a copy of this licence, visit http://creativecommons.org/licenses/by/4.0/.

\section{References}

[1] Jiang C, Li W, Nian J, Lou W, Wang X. Tribological evaluation of environmentally friendly ionic liquids derived from renewable biomaterials. Friction 6(2): 208-218 (2018)

[2] Tu Z, Hu E, Wang B, David K D, Seeger P, Moneke M, Stengler $\mathrm{R}$, $\mathrm{Hu} \mathrm{K}$, $\mathrm{Hu} \mathrm{X}$. Tribological behaviors of Ni-modified citric acid carbon quantum dot particles as a green additive in polyethylene glycol. Friction 8(1): 182-197 (2020)

[3] Singh Y. ribological behavior as lubricant additive and physiochemical characterization of Jatropha oil blends. Friction 3(4): 320-332 (2015)

[4] Ray S S, Bousmina M. Biodegradable polymers and their layered silicate nanocomposites: in green the $21 \mathrm{st}$ century materials word. Prog Mater Sci 50: 962-1079 (2005)

[5] Nourmoradi H, Avazpour M, Ghasemian N, Heidari M, Moradnejadi K, Khodarahmi F, Javaheri M, Mohammadi Moghadam F. Surfactant modified montmorillonite as a low cost adsorbent for 4-chlorophenol: Equilibrium, kinetic and thermodynamic study. J Taiwan Inst Chem Eng 59: 244-251 (2016)

[6] Saurabh C K, Gupta S, Bahadur J, Mazumder S, Variyar P S, Sharma A. Mechanical and barrier properties of guar gumbased nano-composite films. Carbohydr Polymers 124: 77-84 (2015)

[7] Al-Marri M J, Masoud M S, Nassar A M G, Zagho M M, Khader M M. Synthesis and characterization of poly (vinyl alcohol): Cloisite VR 20A nanocomposites. $J$ Vinyl Addit Technol 23: 181-87 (2107)

[8] Alexandre M, Dubois P. Polymer-layered silicate 
nanocomposites: preparation, properties and uses of a new class of materials. Mater Sci Eng R Rep 28; 1-63 (2000)

[9] Cao Z, Xia Y, Xi X. Nano-montmorillonite-doped lubricating grease exhibiting excellent insulating and tribological properties. Friction 5(2): 219-230 (2017)

[10] Martín-Alfonso J E, Valencia C. Tribological, rheological, and microstructural characterization of oleogels based on EVA copolymer and vegetables oils for lubricant applications. Tribol Int 90: 426-434 (2015)

[11] Martín-Alfonso J E, Franco J M. Ethylene-vinyl acetate copolymer (EVA)/sunflower vegetable oil polymer gels: Influence of vinyl acetate content. Polym. Test 37: 78-85 (2014)

[12] Nuñez N, Martín-Alfonso J E, Eugenio M E, Valencia C, Díaz M J, Franco J M. Preparation and characterization of gel-like dispersions based on cellulosic pulps and castor oil for lubricant applications. Ind Eng Chem Res 50: 5618-5627 (2011)

[13] Nuñez N, Martín-Alfonso J E, Eugenio M E, Valencia C, Franco J M, Díaz M J. Influence of eucalyptus globulus kraft pulping severity on the rheological properties of gel-like cellulose pulp dispersions in castor oil. Ind Eng Chem Res 51: 9777-9782 (2012)

[14] Martín-Alfonso J E, Yañez R, Valencia C, Franco J M, Díaz M J. Optimization of the methylation conditions of kraft cellulose pulp for its use as a thickener agent in biodegradable lubricating greases. Ind Eng Chem Res 48: 6765-6771 (2009)

[15] Martín-Alfonso J E, Nuñez N, Valencia C, Franco J M, Díaz M J. Formulation of new biodegradable lubricating greases using ethylated cellulose pulp as thickener agent. $J$ Ind Eng Chem 17: 818-823 (2011)

[16] Gallego R, Arteaga J F, Valencia C, Franco J M. Rheology and thermal degradation of isocyanate-functionalized methyl cellulose-based oleogels. Carbohydr Polym 98: 152-160 (2013)

[17] Gallego R, González M, Arteaga J F, Valencia C, Franco $\mathrm{J}$ M. Influence of functionalization degree on the rheological properties of isocyanate-functionalized chitinand chitosan-based chemical oleogels for lubricant applications. Polymers 6: 1929-1947 (2014)

[18] Gallego R, Arteaga J F, Valencia C, Díaz M J, Franco J M. Gel-like dispersions of HMDI-crosslinked lignocellulosic materials in castor oil: towards completely renewable lubricating grease formulations. ACS Sustain Chem Eng 3: 2130-2121 (2015)

[19] Gallego R, Cidade T, Sánchez R, Valencia C, Franco J M. Tribological behaviour of novel chemically modified biopolymer-thickened lubricating greases investigated in a steel-steel rotating ball-on-three plates tribology cell. Tribol Int 94: 652-660 (2016)

[20] Almdal K, Dyre J, Hvidt S, Kramer, O. Towards a phenomenological definition of the term "gel". Polym Gels Netw 1: 5-17 (1993)

[21] Gupta P K. Polymer and Composite Rheology. New York: Marcel Dekker, 2000

[22] Martín-Alfonso J E, Valencia C, Sánchez M C, Franco J M. Evaluation of thermal and rheological properties of lubricating greases modified with recycled LDPE. Tribol T 55: 518-528 (2012)

[23] Liang B, Li R, Zhang C, Yang Z, Yuan T. Synthesis and characterization of a novel tri-functional bio-based methacrylate prepolymer from castor oil and its application in UV-curable coatings. Ind Crops Prod 135: 170-178 (2019)

[24] Liang D, Zhang Q, Zhang W, Liu L, Liang H, Quirino Rafael L, Chen J, Liu M, Lu Q, Zhang C. Tunable thermo-physical performance of castor oil-based polyurethanes with tailored release of coated fertilizers. J Clean Prod 210: 1207-1215 (2019)

[25] Scaffaro R, Mistretta M C, La Mantia F P, Frache A. Effect of heating of organo-montmorillonites under different atmospheres. Appl Clay Sci 45: 185-193 (2009)

[26] Houtman J, Maisanaba S, Puerto M, Gutiérrez-Praena D, Jordá M, Aucejo S, Jos A. Toxicity assessment of organomodified clays used in food contact materials on human target cell lines. Appl Clay Sci 90: 150-158 (2014)

[27] Ortega F J, Navarro F J, García-Morales M, McNally T. Thermo-mechanical behaviour and structure of novel bitumen/nanoclay/MDI composites. Composites Part B 76: 192-200 (2015)

[28] Lotti C, Isaac C S, Branciforti M C, Alves Rosa M V, Liberman S, Bretas Rosario E S. Rheological, mechanical and transport properties of blown films of high density polyethylene nanocomposites. Eur Polym $J$ 44: 1346-1357 (2008)

[29] National Lubricating Grease Institute. Lubricating greases guide. Kansas City: National Lubricating Grease Institute, 1994.

[30] Martín-Alfonso J E, López-Beltrán F, Valencia C, Franco J M. Effect of an alkali treatment on the development of cellulose pulp-based gel-like dispersions in vegetable oil for use as lubricants. Tribol Int 123: 329-336 (2018)

[31] Thapliyal P, Thakre G D. Correlation study of Physicochemical, rheological, and tribological parameters of engine oils. Adv Tribol 2017: 1-12 (2017) 


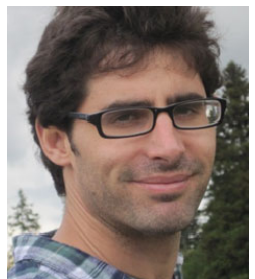

José Enrique MARTÍN ALFONSO. Product Technology Research Center (Pro2TecS) at He received his M.S. and Ph.D. Huelva University since 2012. His current position is a degrees in chemical engineering lecturer and his research areas cover the development from Huelva University, Spain, in 2005 and 2010 respectively. He of nanostructures for different applications, rheology, tribology, and processing of different soft complex joined the Chemical Process and materials (colloids and gels, lubricants, etc.). 